\section{D) Check for updates \\ Cite this: Org. Chem. Front., 2017, 4, 658 \\ Received 24th August 2016, Accepted 26th September 2016 \\ DOI: $10.1039 / c 6 q 000487$ c \\ rsc.li/frontiers-organic}

\title{
Donor- and acceptor-functionalized dibenzo[a,e]pentalenes: modulation of the electronic band gap $\dagger$
}

\author{
J. Wilbuer, ${ }^{a, b}$ D. C. Grenz, ${ }^{a}$ G. Schnakenburg ${ }^{c}$ and B. Esser*a
}

Dibenzo[a,e]pentalene (DBP) is a low-bandgap organic semiconductor. A versatile synthetic route to DBPs substituted with aryl or alkyl groups in the 5,10-positions and electron-donating or -accepting functionalities in the 2,7-positions is described. Six donor- or acceptor-functionalized DBP derivatives were synthesized that show amphoteric redox behavior and band gaps around $2 \mathrm{eV}$. Through choice of the 2,7-substituents, the HOMO/LUMO energy levels and band gaps can be adjusted within a range of up to $0.6 \mathrm{eV}$. In the solid state, the DBP derivatives assume herringbone-type packing structures.

\section{Introduction}

Dibenzo[a,e]pentalene (DBP, 1, Chart 1) is a ladder-type conjugated hydrocarbon that has received a significant amount of attention in recent years. ${ }^{1}$ As organic semiconductors with a low band-gap, derivatives of $\mathbf{1}$ have been employed in organic field-effect transistors (OFETs), exhibiting p-type behavior. ${ }^{2-6}$
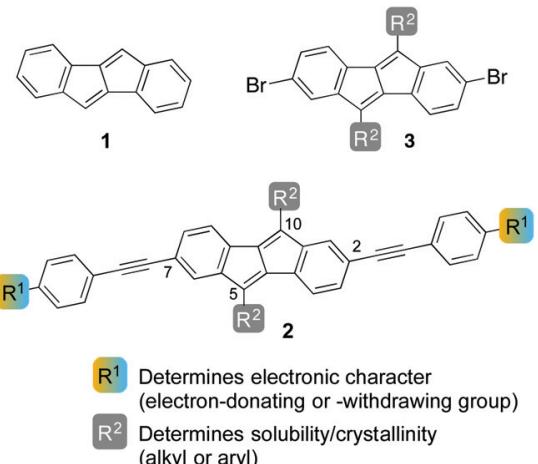

Chart 1 Dibenzo[a,e]pentalene (DBP, 1), donor/acceptor-functionalized DBPs 2 and dibromo-functionalized derivatives 3.

\footnotetext{
${ }^{a}$ Institute for Organic Chemistry, University of Freiburg, Albertstr. 21, 79104 Freiburg, Germany. E-mail: besser@oc.uni-freiburg.de

${ }^{b}$ Kekulé-Institute for Organic Chemistry and Biochemistry, University of Bonn, Gerhard-Domagk-Str. 1, 53121 Bonn, Germany

${ }^{c}$ Institute for Inorganic Chemistry, University of Bonn, Gerhard-Domagk-Str. 1, 53121 Bonn, Germany

$\dagger$ Electronic supplementary information (ESI) available: Experimental details including syntheses, characterization and X-ray crystallographic data as well as details on DFT calculations. CCDC 1496147-1496152. For ESI and crystallographic data in CIF or other electronic format see DOI: 10.1039/c6qo00487c
}

First synthesized in 1912 by Brand, ${ }^{7}$ a variety of methods for the synthesis of DBP derivatives have been developed in the past ten years. ${ }^{8}$ While Brand's original synthesis relies on the addition of Grignard reagents to diphenyl succindandione followed by a two-fold elimination of water, ${ }^{7,9,10}$ derivatives of DBP (1) can now be accessed from (di)aryl-alkynes by reductive $^{11,12}$ or Lewis-acid-induced cyclizations ${ }^{13}$ as well as transition-metal-catalysed or -mediated processes. $^{14-18}$ These methodologies were also applied to the synthesis of $\pi$-extended, ring-fused derivatives of $1 .^{19-22}$ Related hydrocarbons consisting of fused five- and six-membered rings are indeno[1,2-b]fluorenes, ${ }^{23-26}$ bispentalenes, ${ }^{27}$ and other systems that include heteroatoms in the ring structure. ${ }^{28-31}$ In spite of the recent synthetic developments towards DBP derivatives, systematic studies on the modulation of its electronic properties through substitution have been undertaken only twice. Kawase et al. reported on the synthesis and properties of $2,(3) ,7(, 8)$-aryl-substituted DBPs,${ }^{16}$ while Orita and co-workers attached aryl-ethinylenes to the 5,10-positions of the DBP core. ${ }^{32}$ We herein present the synthesis and optoelectronic properties of six DBP derivatives of type 2 (Chart 1), substituted with aryl-alkynes in the 2,7-positions. Electron-donating or -withdrawing groups $\mathrm{R}^{1}$ were chosen that allow for a modulation of the HOMO and LUMO energy levels. The aryl-alkyne groups were attached through posterior modification of the DBP core starting from 2,7-dibromo-DBPs of type 3. Six derivatives of $\mathbf{3}$ as precursors to 2 were synthesized carrying different aryl or alkyl groups in 5,10-position that allow for adapting the solubility properties. The solid-state structure of six DBP derivatives of type $\mathbf{2}$ and $\mathbf{3}$ are presented and discussed.

In order to most strongly influence the HOMO energy of the DBP core, which is relevant for an application as p-type material in OFETs, the $\mathrm{C} 2$ and $\mathrm{C} 7$ positions on the six-mem- 
bered rings were chosen for attachment of the electron-donating or -withdrawing groups, since these possess the largest MO coefficients in the HOMO. ${ }^{33}$ The aryl- $\mathrm{R}^{1}$ substituents were connected to the DBP core through alkyne bridges, since these allow for co-planarity of the latter with the electronically modulating aryl group and hence maximum orbital overlap.

At C5 and C10 of the five-membered rings aryl or alkyl substituents $\mathrm{R}^{2}$ were attached to modulate the solubility and crystallinity of the resulting compounds. A high crystallinity would be advantageous for the charge carrier mobility in OFETs, while a good solubility in common solvents would allow for facile processing of the materials.

\section{Results and discussion}

\section{Syntheses}

For the synthesis of derivatives 3, we chose a method based on Brand's procedure, ${ }^{7}$ since the more recent methods for DBP synthesis do not give access to derivatives suitable for further functionalization, such as 3 with bromo-substituents. ${ }^{32,34}$ Bisbrominated diphenyl succindandione $4,{ }^{6}$ synthesized in an improved synthetic procedure in three steps and 52\% yield from ethyl-4-bromophenylacetate (see ESI $\dagger$ ), was reacted with different Grignard or lithiated alkyl or aryl compounds $\mathrm{R}^{2} \mathrm{M}(\mathrm{X})$ followed by acid-catalysed elimination of water to yield $\mathbf{3 a}-\mathbf{f}$ (Scheme 1). DBP derivatives $\mathbf{3 a}\left(\mathrm{R}^{2}=\mathrm{Me}\right), \mathbf{3 b}\left(\mathrm{R}^{2}=\mathrm{Et}\right)$, and $\mathbf{3 d}$ $\left(\mathrm{R}^{2}=\mathrm{Ph}\right)$ were synthesized through initial addition of the corresponding Grignard reagent to the keto groups in 4 in refluxing toluene, while $3 \mathrm{e}\left(\mathrm{R}^{2}=4\right.$-tert-butylphenyl) was accessed through addition of the corresponding lithiated species. For the synthesis of $\mathbf{3 c}\left(\mathrm{R}^{2}=2\right.$-ethylhexyl) and $\mathbf{3 f}\left(\mathrm{R}^{2}=\right.$
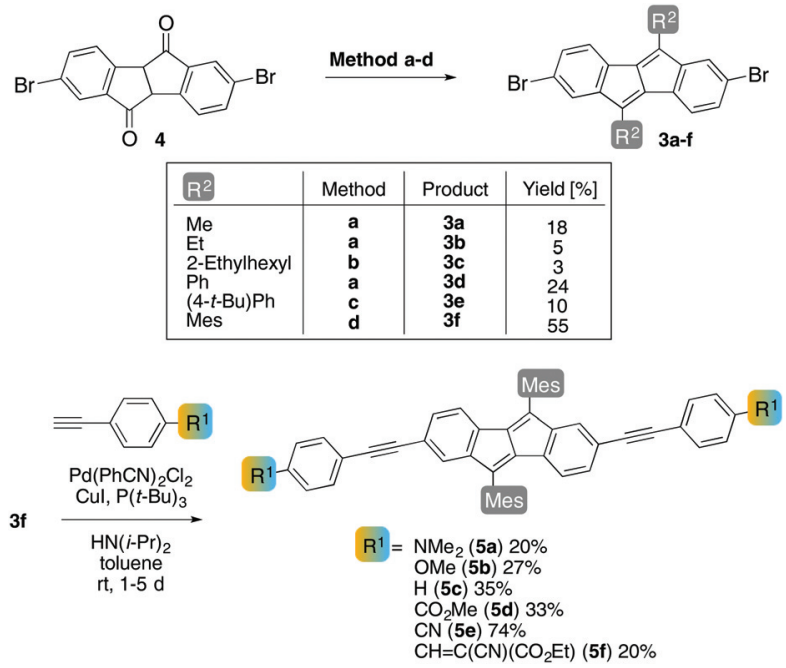

Scheme 1 Synthesis of bis-brominated DBP-derivatives 3a-f and arylalkyne-substituted DBPs $5 a-f$ (Method a: (i) $\mathrm{R}^{2} \mathrm{MgBr}$, toluene, $110{ }^{\circ} \mathrm{C}$, 1-2 h; (ii) $\mathrm{HCl}$ aq., $r t, 0.5-14 \mathrm{~h}$; Method b: (i) $\mathrm{R}^{2} \mathrm{MgBr}, \mathrm{CeCl}_{3}, \mathrm{THF}, 0{ }^{\circ} \mathrm{C}$, $1 \mathrm{~h}$; (ii) $\mathrm{HCl}$ aq., rt, o.n.; Method c: (i) $(4-t-\mathrm{Bu}) \mathrm{PhBr}, n-\mathrm{BuLi}, \mathrm{THF},-50{ }^{\circ} \mathrm{C}$ to rt, $2 \mathrm{~h}$; (ii) $\mathrm{CF}_{3} \mathrm{COOH}$, rt, $2 \mathrm{~d}$; Method d: $1 . \mathrm{R}^{2} \mathrm{MgBr}, \mathrm{CeCl}_{3}, \mathrm{THF}, 0{ }^{\circ} \mathrm{C}$, $8 \mathrm{~h} ; 2$. $p$ - $\mathrm{TsOH}$, toluene, $110^{\circ} \mathrm{C}, 3.5 \mathrm{~h}$ ). mesityl) the addition of cerium trichloride was necessary ${ }^{35}$ for the Grignard addition step to proceed. 3f with mesityl substituents was chosen for further derivatization, since this compound combined the properties of solubility and crystallinity. 3f $\left(\mathrm{R}^{2}=\right.$ Mes) showed a solubility of $4.6 \mathrm{~g} \mathrm{~L}^{-1}$ in dichloromethane and $2.9 \mathrm{~g} \mathrm{~L}^{-1}$ in cyclohexane, while for $3 \mathrm{a}\left(\mathrm{R}^{2}=\mathrm{Me}\right)$ only 1.8 and $0.8 \mathrm{~g} \mathrm{~L}^{-1}$, respectively, dissolved.

The bis-brominated DBPs $\mathbf{3 a}, \mathbf{3} \mathbf{b}$ and $\mathbf{3 d - f}$ were further investigated by X-ray crystallography; their solid-state structures will be discussed below.

Starting from 3f, six different aryl-alkynes with para-substituents $\mathrm{R}^{1}$ were attached to the C2- and C7-positions of the DBP core through Sonogashira cross-coupling reactions to yield 5a-f (Scheme 1). The conditions employed $\left(\mathrm{Pd}(\mathrm{PhCN})_{2} \mathrm{Cl}_{2} /\right.$ $\left.\mathrm{P}(t-\mathrm{Bu})_{3}\right)$ allowed for coupling of the bromides at room temperature. ${ }^{28}$ The aryl-alkynes were chosen based on their electronic properties: two electron-donating (OMe (5b) and $\mathrm{NMe}_{2}$ (5a)), one "neutral" ( $\mathrm{H}(\mathbf{5 c}))$ and three electron-withdrawing $\left(\mathrm{CO}_{2} \mathrm{Me}(\mathbf{5 d}), \mathrm{CN}(\mathbf{5 e})\right.$, and $\left.\mathrm{CHC}(\mathrm{CN})\left(\mathrm{CO}_{2} \mathrm{Et}\right)(\mathbf{5 f})\right)$ substituents. $5 c\left(R^{1}=H\right)$ was further investigated by X-ray crystallography; the structure will be discussed below.

\section{Optoelectronic properties}

(TD)DFT calculations were performed in order to gain information on the orbital energies and electronic transitions in the absorption spectra (see ESI $\dagger$ for details) $\ddagger$ For calculations all mesityl groups in $\mathbf{5 a - f}$ and the ethyl groups in $\mathbf{5 f}$ were replaced by methyl groups, denoted with an asterix $\left(5 \mathbf{a}^{*}-\mathbf{f}^{*}\right)$. Four different density functionals in combination with D3 ${ }^{37,38}$ and the def2$\mathrm{TZVP}^{39}$ basis set were tested with varying amounts of $\mathrm{HF}$ exchange from $0 \%$ to $50 \%$, since this has been shown to have a pronounced effect: ${ }^{40}$ BP86 $^{41-43}(0 \%)$, TPSSH $^{44,45} \quad(10 \%)$, B3LYP $^{46,47}(20 \%)$ and BHLYP ${ }^{48}(50 \%)$. The closest match between TDDFT calculations and experimental absorption spectra was found with B3LYP, while TPSSH gave the best orbital energies (see $\mathrm{ESI} \dagger$ for details), and hence these results will be used in the further discussion. Selected calculated orbital energies of $\mathbf{5 a}^{*}-\mathbf{f}^{*}$ as well as the molecular orbitals of $5 \mathbf{c}^{*}$ are shown in Fig. 1 . With increasing electron-withdrawing character of the substituent $\mathrm{R}^{1}$ the frontier molecular orbital energies of $\mathbf{5 a}^{*}-\mathbf{f}^{*}$ decrease. The HOMO energies experience a stronger shift $(\Delta E=1.0 \mathrm{eV})$ compared to the LUMO energies $(\Delta E=0.88 \mathrm{eV})$, which we had anticipated before based on the size of the MO coefficients in the HOMO and LUMO of DBP (1, see above). The order of decrease in energy of the orbitals from $\mathbf{5} \mathbf{a}^{*}$ to $\mathbf{5} \mathbf{f}^{*}$ corresponds well with the Hammett substitution constants $\sigma$ of $\mathrm{R}^{1}$ : the $\sigma_{\text {para }}$ constants of the substituents $\mathrm{R}^{1}$ amount to -0.83 for $\mathrm{NMe}_{2}\left(5 \mathbf{a}^{*}\right),-0.27$ for OMe $\left(5 \mathbf{b}^{*}\right), 0$ for $\mathrm{H}\left(5 \mathbf{c}^{*}\right), 0.45$ for $\mathrm{CO}_{2} \mathrm{Me}\left(5 \mathbf{d}^{*}\right), 0.66$ for $\mathrm{CN}\left(5 \mathbf{e}^{*}\right)$, and $\sim 0.8 \S$ for $\mathrm{CHC}(\mathrm{CN})\left(\mathrm{CO}_{2} \mathrm{Me}\right)\left(5 \mathbf{f}^{*}\right){ }^{36}$

$\ddagger$ (TD)DFT calculations were performed with the TURBOMOLE 6.6 program package (TURBOMOLE, University of Karlsruhe, Germany, 2012, http://www. turbomole.com).$^{53}$

$\S$ A value of 0.84 was reported for the electronically very similar substituent $\mathrm{CHC}(\mathrm{CN})(\mathrm{CN}){ }^{36}$ 

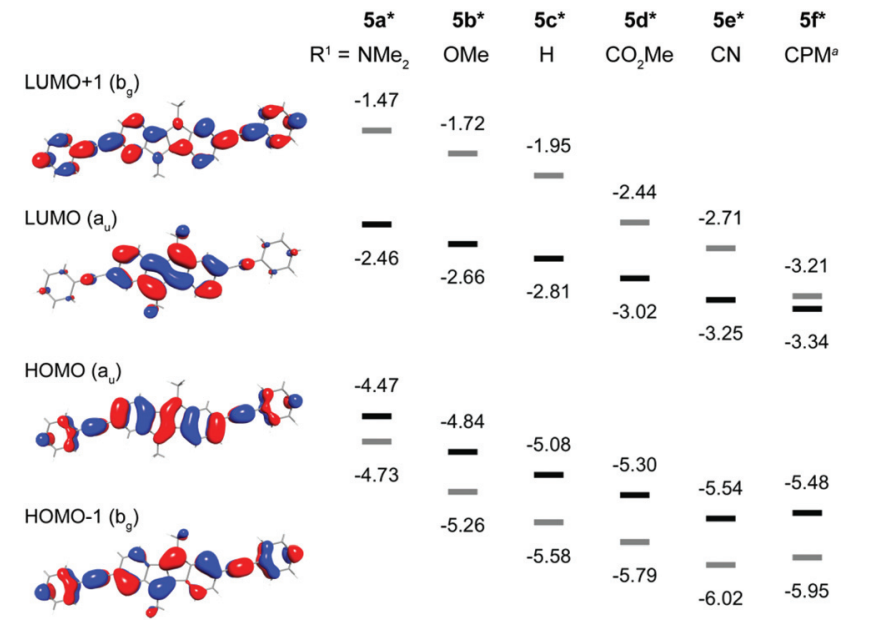

Fig. 1 Molecular orbitals of $5 c^{*}\left(R^{1}=H\right.$, left) and energy diagram (eV, right) of calculated MOs of DBP derivatives $5 a^{*}-f^{*}$ (TPSSH-D3/def2TZVP, $\left.{ }^{a} \mathrm{CPM}=\mathrm{CHC}(\mathrm{CN})\left(\mathrm{CO}_{2} \mathrm{Me}\right)\right)$.

The absorption spectra of $\mathbf{5 a - f}$ are displayed in Fig. 2. All derivatives show three characteristic absorption bands, which were assigned to electronic transitions using TDDFT calculations (B3LYP-D3/def2-TZVP). The lowest energy bands from 470-700 $\mathrm{nm}$, well visible on the logarithmic scale in the inset in Fig. 2, can be ascribed to the HOMO $\rightarrow$ LUMO transitions $\left(S_{0}\right.$ to $\left.S_{1}\right)$. These transitions are symmetry forbidden, since both orbitals are of $a_{\mathrm{u}}$ symmetry (Laporte's rule, see also Fig. 1), which is reflected in the relatively low absorption coefficients of $\log \varepsilon=2.9-3.4$. This low energy band appears at very similar wavelengths for all substituents with maxima from 530-534 $\mathrm{nm}$ except for $\mathbf{5 a}$ and $\mathbf{5 f}$. The $\mathrm{NMe}_{2}$ substituent in $\mathbf{5 a}$ affects a bathochromic shift to $567 \mathrm{~nm}$, while the $\mathrm{CHC}(\mathrm{CN})$ $\left(\mathrm{CO}_{2} \mathrm{Et}\right)$ substituent in $\mathbf{5 f}$ leads to a hypsochromic shift to $511 \mathrm{~nm}$. The second absorption bands from 380-470 nm can be assigned to the HOMO-1 $\rightarrow$ LUMO, HOMO-2 $\rightarrow$ LUMO and other transitions, while the most intense $(\log \varepsilon=5.0-5.1)$

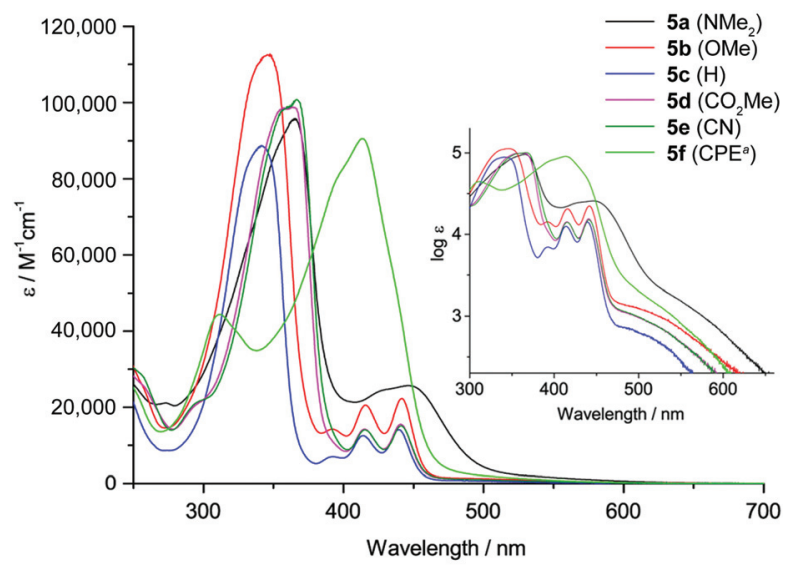

Fig. 2 Absorption spectra of $5 a-f$ in $\mathrm{CH}_{2} \mathrm{Cl}_{2}$ solution $\left({ }^{a} \mathrm{CPE}=\mathrm{CHC}(\mathrm{CN})\right.$ $\left.\left(\mathrm{CO}_{2} \mathrm{Et}\right)\right)$. Inset: Spectra plotted on a logarithmic scale.
Table 1 Electrochemical and optical data for aryl-alkyne-substituted DBPs $5 a-f$

\begin{tabular}{lllllll}
\hline & $\begin{array}{l}E_{\text {red 1/2 }} \\
(\mathrm{V})\end{array}$ & $\begin{array}{l}E_{\mathrm{Ox} \mathrm{1/2}} \\
(\mathrm{V})\end{array}$ & $\begin{array}{l}E_{\mathrm{HOMO}}{ }^{a} \\
(\mathrm{eV})\end{array}$ & $\begin{array}{l}E_{\mathrm{LUMO}}{ }^{a} \\
(\mathrm{eV})\end{array}$ & $\begin{array}{l}E_{\mathrm{g}} \\
(\mathrm{eV})\end{array}$ & $\begin{array}{l}E_{\mathrm{g}}(\mathrm{opt})^{b} \\
(\mathrm{eV})\end{array}$ \\
\hline $\mathbf{5 a}$ & -1.79 & $0.39^{c}$ & -5.17 & -3.18 & 1.99 & 1.82 \\
$\mathbf{5 b}$ & -1.77 & 0.78 & -5.57 & -3.18 & 2.39 & 1.99 \\
$\mathbf{5 c}$ & -1.74 & 0.83 & -5.68 & -3.22 & 2.46 & 2.08 \\
$\mathbf{5 d}$ & -1.71 & 0.93 & -5.73 & -3.27 & 2.46 & 2.07 \\
$\mathbf{5 e}$ & -1.67 & 0.98 & -5.77 & -3.28 & 2.49 & 2.07 \\
$\mathbf{5 f}$ & $-1.68^{d}$ & 0.89 & -5.69 & -3.34 & 2.35 & 1.95 \\
& -1.79 & & & & &
\end{tabular}

${ }^{a}$ From the onset of the reduction/oxidation peak $v s$. $\mathrm{Fc} / \mathrm{Fc}^{+}$, assuming an ionization energy of $4.8 \mathrm{eV}$ for ferrocene.$^{50}{ }^{b}$ From the onset of the longest wavelength absorption band. ${ }^{c}$ Cathodic peak potential. ${ }^{d}$ Anodic peak potential.

and highest energy absorption bands from 270-380 $\mathrm{nm}$ can be attributed to the HOMO $\rightarrow$ LUMO+1 transitions. The $\mathrm{CHC}(\mathrm{CN})$ $\left(\mathrm{CO}_{2} \mathrm{Et}\right)$ substituent presents an exception, since the most intense absorption is the HOMO-1 $\rightarrow$ LUMO transition at $414 \mathrm{~nm}$. Overall, the $\mathrm{NMe}_{2}$-substituted derivative 5a experiences the strongest bathochromic shift of all absorption bands. This is in accordance with the electrochemical results and calculations that show a strong increase in HOMO (and HOMO-1) energy relative to the other derivatives, while the LUMO energy is less strongly affected (see also Fig. 1 and Table 1). This observation is in agreement with our initial assumption, that substitution at the 2,7-positions of the DBP core would most strongly affect the HOMO energy level (see above). The optical transitions in $\mathbf{5 f}$ are different compared to 5a-e, likely due to the extended conjugation into the $\mathrm{CHC}(\mathrm{CN})\left(\mathrm{CO}_{2} \mathrm{Et}\right)$ substituent. The band gaps of $\mathbf{5 a - f}$ were obtained from the onset of the longest wavelength absorption and are listed in Table 1 . None of the DBP derivatives 5a-f showed fluorescence. This has also been observed for the indeno[1,2- $b]$ fluorenes, in which case it was rationalized through transient absorption spectroscopy measurements that showed that the excited state lifetimes were shorter than the timescale at which fluorescence is observed. ${ }^{49}$

The electrochemical properties of $\mathbf{5 a - f}$ were investigated through cyclic voltammetry measurements in $\mathrm{CH}_{2} \mathrm{Cl}_{2}$ solution (Fig. 3 and Table 1), 1 where the first oxidation and reduction can be used to determine the HOMO and LUMO energies, respectively. All DBP derivatives 5a-f show amphoteric redox behaviour. The redox potentials correspond well with the electron-donating or -withdrawing character of the substituents $\mathrm{R}^{1}$ : $\mathrm{CO}_{2} \mathrm{Me}(\mathbf{5 d}), \mathrm{CN}(\mathbf{5 e})$ and $\mathrm{CHC}(\mathrm{CN})\left(\mathrm{CO}_{2} \mathrm{Et}\right)(\mathbf{5 f})$ lead to a positive shift in reduction and oxidation potential relative to 5c with $\mathrm{R}^{1}=\mathrm{H}$, while this trend is reversed for the OMe (5b) and $\mathrm{NMe}_{2}$ (5a) substituents. The $\mathrm{NMe}_{2}$ substituent significantly lowers the oxidation potential and hence the HOMO

ๆ Large peak separations might be due to a temperature effect (CVs were measured in the glove box at $25-30^{\circ} \mathrm{C}$ ) or the specific cell setup. 


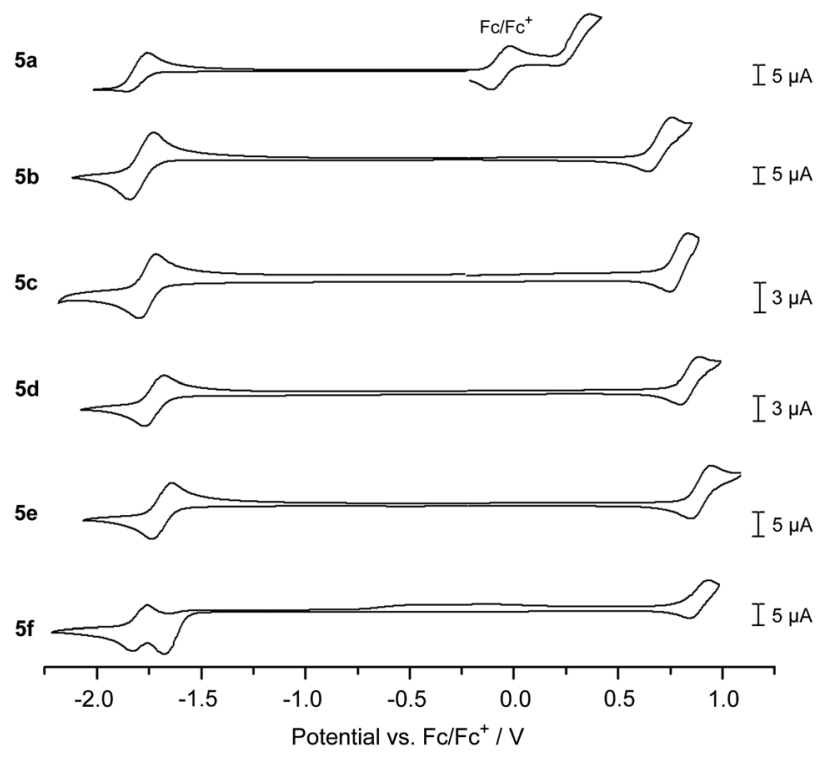

Fig. 3 Cyclic voltammograms of $5 \mathrm{a}-\mathrm{f}\left(1 \mathrm{~mm}^{*}\right.$ in $\mathrm{CH}_{2} \mathrm{Cl}_{2}, 0.1 \mathrm{~m}$ $n-\mathrm{Bu}_{4} \mathrm{NPF}_{6}$, scan rate $0.1 \mathrm{~V} \mathrm{~s}^{-1}$ (for $5 \mathrm{c} 0.2 \mathrm{~V} \mathrm{~s}^{-1}$ ), $5 \mathrm{c}, 5 \mathrm{~d}$, and $5 \mathrm{e}$ with a Pt-electrode, 5b, 5a, and $\mathbf{5 f}$ with a GC-electrode). $\mid$ *Due to solubility issues the concentration of $5 a$ was lower.

energy of $5 \mathbf{a}$ by $\Delta E_{\mathrm{HOMO}}=0.51 \mathrm{eV}$ relative to $5 \mathbf{c}\left(\mathrm{R}^{1}=\mathrm{H}, E_{\mathrm{HOMO}}\right.$ $=-5.68 \mathrm{~V})$. For $5 \mathbf{f}\left(\mathrm{R}^{1}=\mathrm{CHC}(\mathrm{CN})\left(\mathrm{CO}_{2} \mathrm{Et}\right)\right)$ two reduction waves were observed, of which the first one was not reversible. This might be related to the close proximity in energy of the LUMO and LUMO+1, as found in DFT calculations (see Fig. 1). For all derivatives the electrochemically determined band gaps are larger than the optical band gaps, which has been observed for other non-alternant hydrocarbons ${ }^{51}$ before. ${ }^{52}$

Our investigations show that by attaching electron-donating or -withdrawing substituents to the 2,7-positions of DBP, its electronic properties can be significantly modulated. The HOMO energies show the largest effect, as anticipated, with a difference of $0.60 \mathrm{eV}$ between $5 \mathbf{a}$ and $5 \mathbf{e}$, while the LUMO energies vary within $0.16 \mathrm{eV}$ (5a vs. 5f).

\section{Structural properties}

The molecular packing in the solid state is important for the performance of organic semiconductors in electronics devices. The solid-state structures of six of the synthesized DBP derivatives were investigated by X-ray crystallography. || Single crystals suitable for X-ray diffraction were obtained by slow evaporation of solutions in $\mathrm{CH}_{2} \mathrm{Cl}_{2}$ (3a, d, e), $\mathrm{CDCl}_{3}$ (3b), EtOAc/cyclohexane (3f) or $\mathrm{CHCl}_{3}(\mathbf{5 c})$. The molecular structures of $5 \mathbf{c}, 3 \mathbf{a}$, $\mathbf{3 b}$ and $\mathbf{3 f}$ are shown in Fig. 4 (see $\mathrm{ESI} \dagger$ for $\mathbf{3 d}$ and $3 \mathbf{e}$ ). In all derivatives, the DBP core assumes an almost planar conformation. The phenyl-alkyne substituents in 5c are slightly rotated relative to the DBP core by $\sim 25^{\circ}$. The dihedral angle

||CCDC numbers 1496147 (3a), 1496148 (3b), 1496149 (3d), 1496150 (3e), 1496151 (3f), and 1496152 (5c) contain the supplementary crystallographic data for this paper.

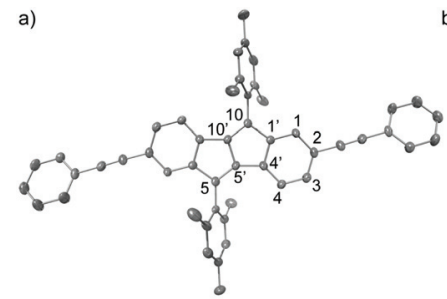

c)

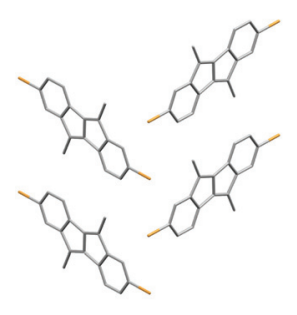

d)

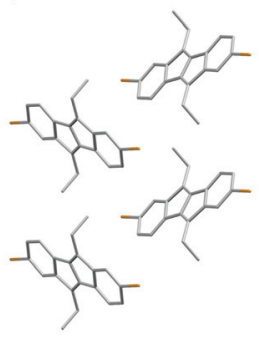

b)

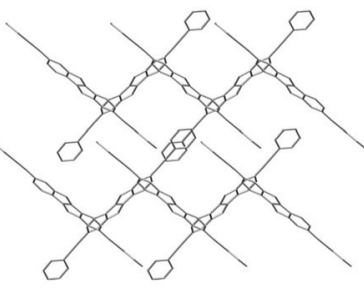

e)

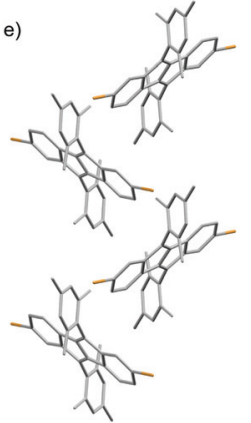

Fig. 4 Molecular structure of $5 c(a)$ and packing diagrams of $5 c(b), 3 a$ (c), $3 \mathrm{~b}(\mathrm{~d})$, and $3 \mathrm{f}(\mathrm{e})$ in the solid state (viewed along the crystallographic a-axis, hydrogen atoms and mesityl groups (in b) are omitted for clarity, ORTEP ellipsoids (in a) are shown at $50 \%$ probability).

between the mesityl groups and the DBP core amounts to $\sim 70^{\circ}$ due to steric hindrance associated with the two ortho-methyl groups. Hence electronic communication through $\pi$-orbital overlap between the mesityl groups and the DBP core can be excluded. The bond lengths in the six-membered rings of the DBP core in 5c are relatively homogeneous (1.377-1.431 A), while in the five-membered rings the $\mathrm{C} 10-\mathrm{C} 10^{\prime}$ bond is short (1.362 $⿱$ A) and the $\mathrm{C} 5^{\prime}-\mathrm{C} 10^{\prime}, \mathrm{C} 4^{\prime}-\mathrm{C} 5^{\prime}$ and $\mathrm{C} 1^{\prime}-\mathrm{C} 10$ bonds are comparably long (1.464-1.477 $\AA$ ). In the crystal lattice 5c assumes a herringbone pattern, in which the planes of the DBP cores of two non-parallel aligned molecules are oriented at an angle of $\sim 70^{\circ}$ (Fig. 4b). 3a, b, and $\mathbf{f}$ also assume herringbone-type packing structures in the solid state (Fig. 4c-e). The distances between to parallel aligned molecules, viewed along the crystallographic $a$-axis, amount to $3.19 \AA$ for $3 \mathrm{a}, 3.38 \AA$ for 3b, and $4.26 \AA$ for $3 f$.

\section{Conclusions}

In summary, we have established a versatile synthetic route to 2,7-dibromo-functionalized dibenzo[a,e]pentalenes 3 with aryl or alkyl substituents in 5,10-position that can be further derivatized through cross-coupling reactions. Six electron-donating or -accepting aryl alkynes were attached through Sonogashira reactions, and the resulting 2,7-aryl-alkyne-substituted DBPs 5a-f were investigated regarding their optoelectronic properties. The choice of the substituent allowed modulating the HOMO or LUMO energy level within a range of $0.60 \mathrm{eV}$ or 0.16 $\mathrm{eV}$, respectively, and the band gap within a range of $0.26 \mathrm{eV}$. In the solid state, the DBP derivatives $3 \mathbf{a}, 3 \mathbf{b}, \mathbf{3 f}$ and $\mathbf{5 c}$ assume herringbone-type packing structures. The compounds show 
amphoteric redox behaviour and are attractive candidates for application in organic electronics devices.

\section{Acknowledgements}

We thank C. Rödde of the single crystal X-ray diffraction service. Generous support by the German Research Foundation (Emmy Noether program, ES 361/2-1), the Chemical Industry Trust (Liebig Fellowship, Li 189/11) and the University of Bonn (Maria von Linden-program) is gratefully acknowledged.

\section{Notes and references}

1 H. Hopf, Angew. Chem., Int. Ed., 2013, 52, 1222412226.

2 C. Liu, S. Xu, W. Zhu, X. Zhu, W. Hu, Z. Li and Z. Wang, Chem. - Eur. J., 2015, 21, 17016-17022.

3 G. Dai, J. Chang, W. Zhang, S. Bai, K.-W. Huang, J. Xu and C. Chi, Chem. Commun., 2015, 51, 503-506.

4 T. Kawase, T. Fujiwara, C. Kitamura, A. Konishi, Y. Hirao, K. Matsumoto, H. Kurata, T. Kubo, S. Shinamura, H. Mori, E. Miyazaki and K. Takimiya, Angew. Chem., Int. Ed., 2010, 49, 7728-7732.

5 C. Li, C. Liu, Y. Li, X. Zhu and Z. Wang, Chem. Commun., 2015, 51, 693-696.

6 M. Nakano, I. Osaka, K. Takimiya and T. Koganezawa, J. Mater. Chem. C, 2014, 2, 64-70.

7 K. Brand, Chem. Ber., 1912, 45, 3071-3077.

8 M. Saito, Symmetry, 2010, 2, 950-969.

9 K. Brand and F. W. Hoffmann, Chem. Ber., 1920, 53, 815-821.

10 K. Brand and F. Schläger, Chem. Ber., 1923, 56, 2541-2545.

11 M. Saito, M. Nakamura, T. Tajima and M. Yoshioka, Angew. Chem., Int. Ed., 2007, 46, 1504-1507.

12 H. Zhang, T. Karasawa, H. Yamada, A. Wakamiya and S. Yamaguchi, Org. Lett., 2009, 11, 3076-3079.

13 C. Chen, M. Harhausen, R. Liedtke, K. Bussmann, A. Fukazawa, S. Yamaguchi, J. L. Petersen, C. G. Daniliuc, R. Fröhlich, G. Kehr and G. Erker, Angew. Chem., Int. Ed., 2013, 52, 5992-5996.

14 A. S. K. Hashmi, M. Wieteck, I. Braun, P. Nösel, L. Jongbloed, M. Rudolph and F. Rominger, Adv. Synth. Catal., 2012, 354, 555-562.

15 Z. U. Levi and T. D. Tilley, J. Am. Chem. Soc., 2009, 131, 2796-2797.

16 T. Kawase, A. Konishi, Y. Hirao, K. Matsumoto, H. Kurata and T. Kubo, Chem. - Eur. J., 2009, 15, 2653-2661.

17 T. Maekawa, Y. Segawa and K. Itami, Chem. Sci., 2013, 4, 2369-2373.

18 J. Zhao, K. Oniwa, N. Asao, Y. Yamamoto and T. Jin, J. Am. Chem. Soc., 2013, 135, 10222-10225.

19 Z. U. Levi and T. D. Tilley, J. Am. Chem. Soc., 2010, 132, 11012-11014.
20 H. Li, X.-Y. Wang, B. Wei, L. Xu, W.-X. Zhang, J. Pei and Z. Xi, Nat. Commun., 2014, 5, 4508.

21 F. Xu, L. Peng, K. Shinohara, T. Nishida, K. Wakamatsu, M. Uejima, T. Sato, K. Tanaka, N. Machida, H. Akashi, A. Orita and J. Otera, Org. Lett., 2015, 17, 3014-3017.

22 J. Shen, D. Yuan, Y. Qiao, X. Shen, Z. Zhang, Y. Zhong, Y. Yi and X. Zhu, Org. Lett., 2014, 16, 4924-4927.

23 D. T. Chase, B. D. Rose, S. P. McClintock, L. N. Zakharov and M. M. Haley, Angew. Chem., Int. Ed., 2011, 50, 1127-1130.

24 D. T. Chase, A. G. Fix, S. J. Kang, B. D. Rose, C. D. Weber, Y. Zhong, L. N. Zakharov, M. C. Lonergan, C. Nuckolls and M. M. Haley, J. Am. Chem. Soc., 2012, 134, 10349-10352.

25 T. Maekawa, H. Ueno, Y. Segawa, M. M. Haley and K. Itami, Chem. Sci., 2016, 7, 650-654.

26 J. L. Marshall, N. J. O'Neal, L. N. Zakharov and M. M. Haley, J. Org. Chem., 2016, 81, 3674-3680.

27 J. Cao, G. London, O. Dumele, M. von Wantoch Rekowski, N. Trapp, L. Ruhlmann, C. Boudon, A. Stanger and F. Diederich, J. Am. Chem. Soc., 2015, 137, 7178-7188.

28 J. D. Wood, J. L. Jellison, A. D. Finke, L. Wang and K. N. Plunkett, J. Am. Chem. Soc., 2012, 134, 15783-15789.

29 X.-Y. Wang, A. Narita, X. Feng and K. Müllen, J. Am. Chem. Soc., 2015, 137, 7668-7671.

30 A. Konishi, T. Fujiwara, N. Ogawa, Y. Hirao, K. Matsumoto, H. Kurata, T. Kubo, C. Kitamura and T. Kawase, Chem. Lett., 2010, 39, 300-301.

31 G. Dai, J. Chang, J. Luo, S. Dong, N. Aratani, B. Zheng, K. W. Huang, H. Yamada and C. Chi, Angew. Chem., Int. Ed., 2016, 55, 2693-2696.

32 F. Xu, L. Peng, A. Orita and J. Otera, Org. Lett., 2012, 14, 3970-3973.

33 B. Esser, Phys. Chem. Chem. Phys., 2015, 17, 7366-7372.

34 J.-J. Shen, J.-Y. Shao, X. Zhu and Y.-W. Zhong, Org. Lett., 2015, 18, 256-259.

35 T. Imamoto, N. Takiyama, K. Nakamura, T. Hatajima and Y. Kamiya, J. Am. Chem. Soc., 1989, 111, 4392-4398.

36 C. Hansch, A. Leo and R. W. Taft, Chem. Rev., 1991, 91, 165-195.

37 S. Grimme, J. Antony, S. Ehrlich and H. Krieg, J. Chem. Phys., 2010, 132, 154104.

38 S. Grimme, S. Ehrlich and L. Goerigk, J. Comput. Chem., 2011, 32, 1456-1465.

39 A. Schäfer, C. Huber and R. Ahlrichs, J. Chem. Phys., 1994, 100, 5829-5835.

40 G. Zhang and C. B. Musgrave, J. Phys. Chem. A, 2007, 111, 1554-1561.

41 A. D. Becke, Phys. Rev. A, 1988, 38, 3098-3100.

42 J. P. Perdew, Phys. Rev. B: Condens. Matter, 1986, 33, 8822-8824.

43 J. P. Perdew, Phys. Rev. B: Condens. Matter, 1986, 34, 7406.

44 J. Tao, J. P. Perdew, V. N. Staroverov and G. E. Scuseria, Phys. Rev. Lett., 2003, 91, 146401.

45 V. N. Staroverov, G. E. Scuseria, J. Tao and J. P. Perdew, J. Chem. Phys., 2003, 119, 12129.

46 P. J. Stephens, F. J. Devlin, C. F. Chabalowski and M. J. Frisch, J. Phys. Chem., 1994, 98, 11623-11627. 
47 A. D. Becke, J. Chem. Phys., 1993, 98, 5648-5652.

48 A. D. Becke, J. Chem. Phys., 1993, 98, 1372-1377.

49 B. D. Rose, L. E. Shoer, M. R. Wasielewski and M. M. Haley, Chem. Phys. Lett., 2014, 616-617, 137-141.

50 B. W. D'Andrade, S. Datta, S. R. Forrest, P. Djurovich, E. Polikarpov and M. E. Thompson, Org. Electron., 2005, 6, 11-20.
51 R. Gleiter and G. Haberhauer, Aromaticity and Other Conjugation Effects, Wiley-VCH, Weinheim, Germany, 2012.

52 X. Yang, X. Shi, N. Aratani, T. P. Goncalves, K.-W. Huang, H. Yamada, C. Chi and Q. Miao, Chem. Sci., 2016, 7, 61766181.

53 R. Ahlrichs, M. Bär, H. Marco, H. Horn and C. Kölmel, Chem. Phys. Lett., 1989, 162, 165-169. 